\title{
INTERACTION OF BUILDING AND GROUND DURING AN EARTHQUAKE
}

\author{
By George W. Housner
}

A PoINT of much interest to engineers is the interaction of a building and the ground during an earthquake. There are several facets of this problem that have a bearing on the stresses produced in a building during an earthquake. First, there is the question of the influence of the building on recorded ground motion. The majority of the accelerometers for recording strong ground motion are in the basements of buildings and hence record the motion of the base of the building. The question thus arises, How much does this recorded motion differ from that which would have been recorded at the site had there been no building? If there should be a marked difference between the motion recorded within a building and that recorded directly on the surface of the ground, there would be a possibility of designing a building so as to minimize the base motion it would receive during an earthquake.

Another consideration is the coupling between an oscillating building and the ground. When a building vibrates, it stresses the ground on which it rests, and because of these stresses the base of the building moves. This base motion has an effect upon the vibrational properties of the building and hence an effect upon the stresses developed during an earthquake. The two most significant forms of buildingand-ground coupling are the rocking of the building on its base and the horizontal displacement of the base of the building. The rocking motion of a building has been investigated, ${ }^{1}$ and it was found that significant effects could be expected only with exceptionally soft ground. The horizontal displacement of the bases of buildings produced by ground coupling has not been specifically investigated in this country. However, analyses of accelerograms obtained in basements of buildings do not indicate any marked horizontal ground coupling.

During the Arvin-Tehachapi earthquake of July 21, 1952, some ground and building accelerations were recorded that contain interesting information about the interaction of building and ground. This paper presents the results of analyses of these accelerograms.

The pertinent accelerograms were obtained in the basement of the Hollywood Storage Company building and on the surface of the ground near the building, and in the basement of the Athenaeum building on the campus of the California Institute of Technology in Pasadena. Both of these locations are approximately 75 miles due south of the epicenter, and are 12 miles apart in the east-west direction. Because of the relatively large distance from the epicenter the ground motions were not severe, the maximum accelerations being 4 to 5 per cent of gravity, which can be compared with the 20 to 30 per cent of gravity that have been recorded near the epicenters of strong shocks. Detailed information on the July 21, 1952, earthquake and the damage it caused has appeared in several publications. ${ }^{2}$

\footnotetext{
Manuscript received for publication August 28, 1956.

1 R. G. Merritt and G. W. Housner, "Effect of Foundation Compliance on Earthquake Stresses in Multistory Buildíngs," Bull. Seism. Soc. Am., Vol. 44, No. 4 (1954).

2 "Earthquakes in Kern County, California, during 1952," State of California Division of Mines,
} 


\section{The Buildings and Sites}

The Hollywood Storage Company building is a monolithic, reinforced concrete structure $141 \mathrm{ft}$. high plus a basement. There are very few windows in the walls; it is essentially a concrete box. The building is rectangular in plan (as is shown in the accompanying drawing), measuring $217 \mathrm{ft}$. in the east-west direction and $51 \mathrm{ft}$.

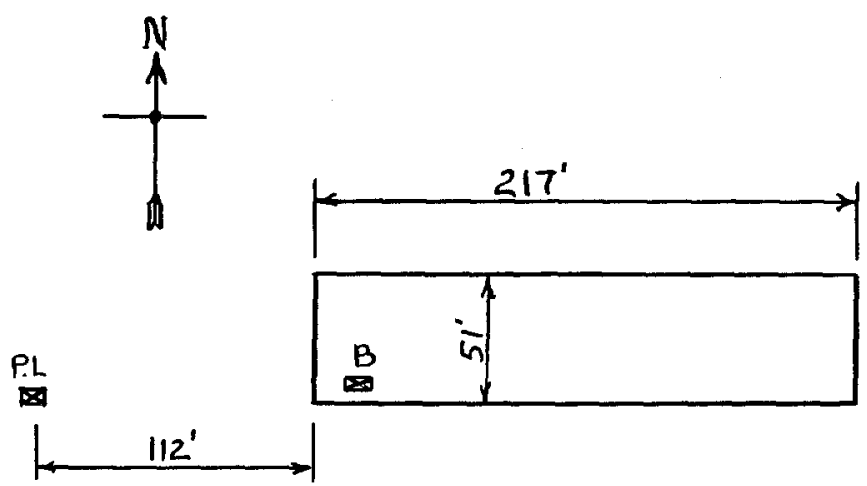

Plan of the Hollywood Storage Company building. "B" and "P.L." mark position of accelerographs in basement and parking lot. The epicenter of the earthquake of July 21, 1952, was located 75 miles distant on a line $\mathrm{N} 20^{\circ} \mathrm{W}$.

in the north-south direction. The building is supported on a pile foundation in relatively soft alluvium. One accelerometer was on the floor of the basement, and another in a $6 \mathrm{ft}$. by $9 \mathrm{ft}$. galvanized iron shed $112 \mathrm{ft}$. west of the building in a parking lot. These locations are shown in the drawing, where the accelerometers are marked B and P.L.

The periods of vibration of the building have been measured. ${ }^{3}$ The fundamental period in the north-south direction was found to be 1.2 sec., and that in the eastwest direction, $0.49 \mathrm{sec}$.

The Athenaeum building in Pasadena is a reinforced concrete structure of two stories plus basement. It rests on a layer of moderately firm alluvium approximately $900 \mathrm{ft}$. deep. The accelerometer was on the floor of the basement.

\section{The AcCelerograms}

Figures 1 and 2 show the initial portions of the north-south and east-west components of ground acceleration recorded in the basement of the Hollywood Storage building and in the parking lot. The Pasadena accelerograms are not reproduced, but their general appearance is very similar to that of the Hollywood Storage records. The corresponding components of ground acceleration (figs. $1, a$ and $b ; 2$, $a$ and $b$ ) have been reproduced together to facilitate comparison. Inspection shows

Bull. 171 (1955); K. V. Steinbrugge and D. F. Moran, "An Engineering Study of the Southern California Earthquake of July 21, 1952, and Its Aftershocks," Bull. Seism. Soc. Am., Vol. 44, No. 2B (1954).

3 D. S. Carder and I. S. Jacobsen, "Vibration Observations, Earthquake Investigations in California, 1934-35," U. S. Dept. Commerce, Coast and Geodetic Survey, Serial Publ. 201 (1936). 
that the accelerograms obtained within and outside the building are very similar in appearance and that although the building was large, heavy, and stiff, and rested on relatively soft soil there is no obvious difference to be seen between the accelerograms recorded in the building and those recorded in the parking lot.

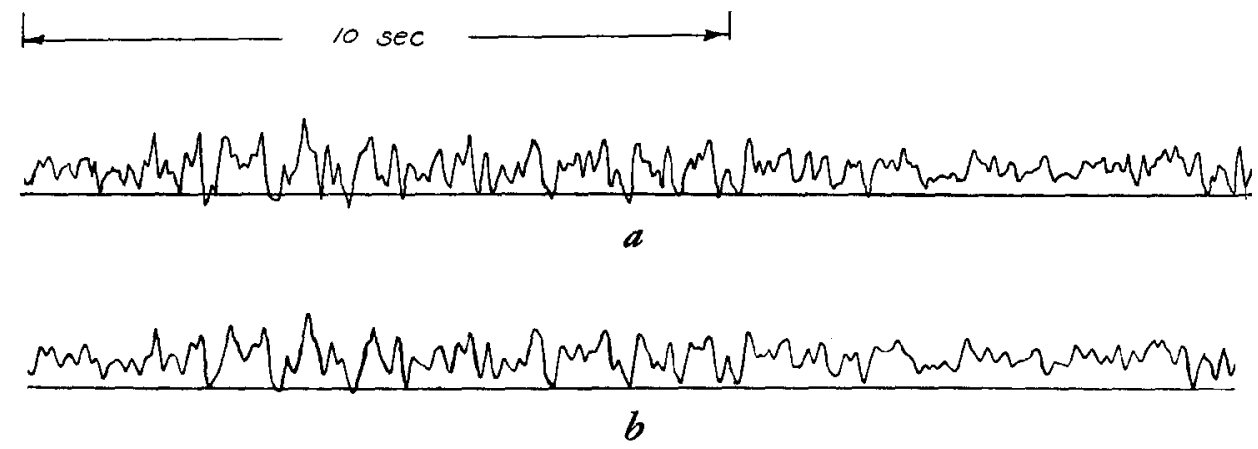

Fig. 1. $a$, Hollywood Storage parking lot, N-S ground acceleration; $b$, Hollywood Storage basement, N-S ground acceleration.

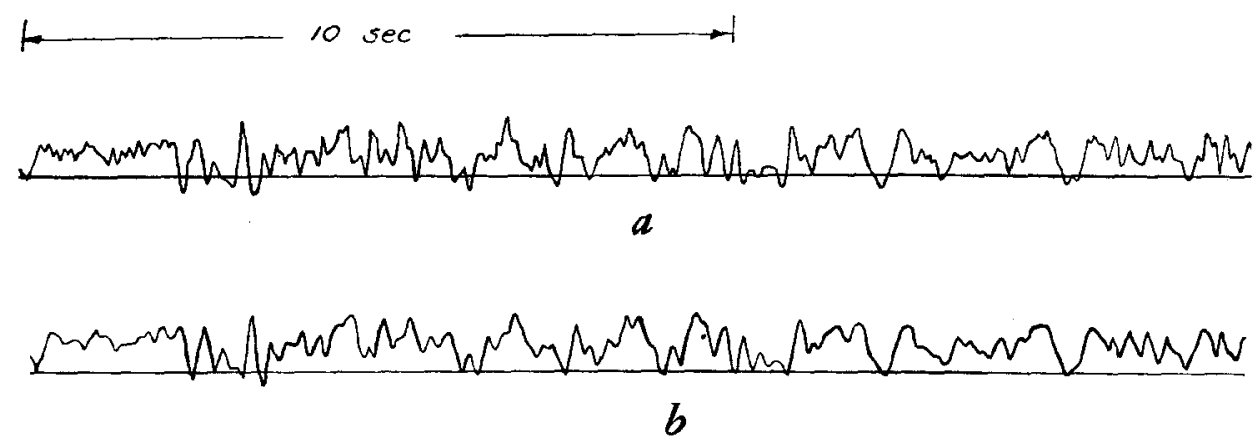

Fig. 2. a, Hollywood Storage parking lot, $\mathrm{E}-\mathrm{W}$ ground acceleration; $b$, Hollywood Storage basement, $\mathbf{E}-\mathbf{W}$ ground acceleration.

\section{Analysis of ACCElerograms}

A detailed inspection of the accelerograms shows some differences in amplitudes and in the strength of the high-frequency components. To exhibit these differences, velocity-spectrum curves were computed in the same manner as for previous earthquake records. ${ }^{4}$ The spectra curves are the plotted values of

$$
\begin{aligned}
S & =\left(\int_{0}^{t} a \exp \left[-n \frac{2 \pi}{T}(\mathrm{t}-\tau)\right] \sin \frac{2 \pi}{T}(t-\tau) d \tau\right) \max . \\
a & =\text { ground acceleration } \\
n & =\text { fraction of critical damping } \\
T & =\text { period } \\
t & =\text { time }
\end{aligned}
$$

${ }^{4}$ G. W. Housner, R. R. Martel, and J. L. Alford, "Spectrum Analysis of Strong-Motion Earthquakes," Bull. Seism. Soc. Am., Vol. 43, No. 2 (1953). 


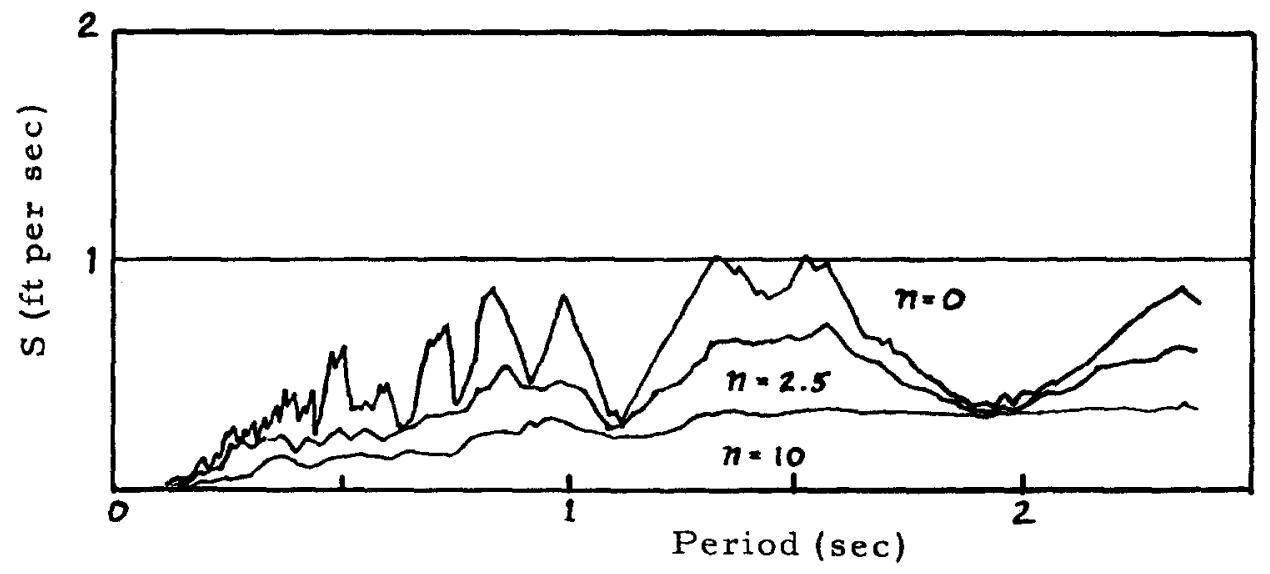

Fig. 3. Spectrum, Hollywood Storage basement; component E-W.

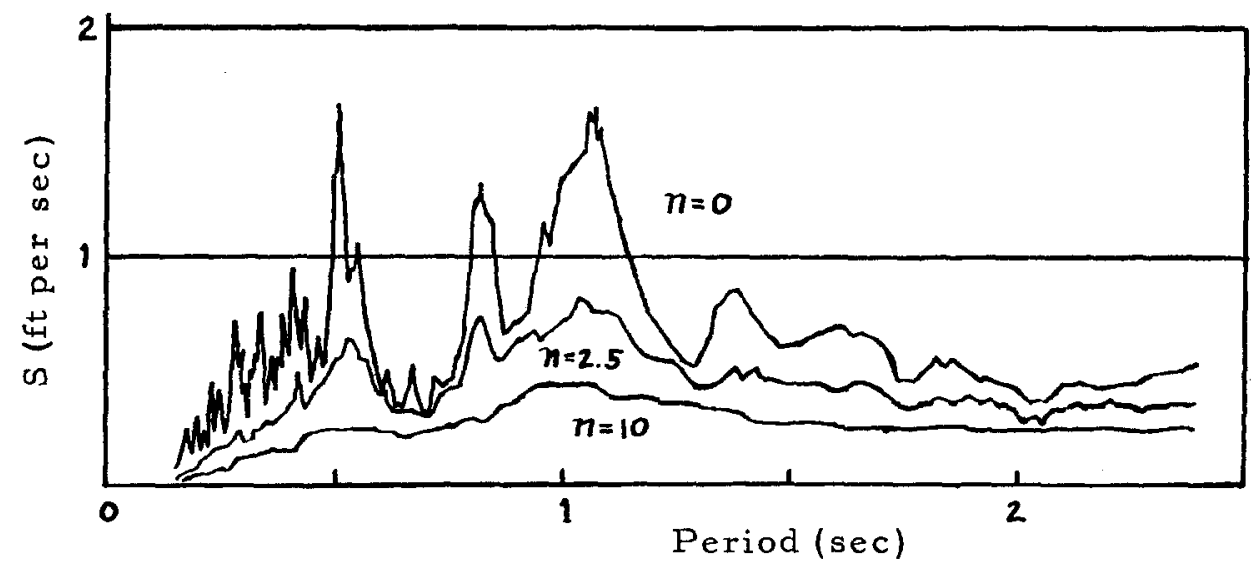

Fig. 4. Spectrum, Hollywood Storage basement; component N-S.

The spectrum curves shown in figures 3 to 10 are plots of the maximum value of equation (1) for $n=0$ per cent, 2.5 per cent, and 10 per cent of critical damping over a range of periods from 0.1 to 2.5 sec. It will be noted that $2 \pi S / T$ gives, essentially, the maximum acceleration of a one-degree-of-freedom structure of appropriate $n$ and $T$ when subjected to the ground acceleration; $S$ is the maximum velocity attained by the structure. The spectra of figures 3 to 10 thus exhibit the maximum response of a structure to the ground motion, and if there are any significant differences between the accelerations recorded in the basement and in the parking lot they will be shown by the spectrum curves.

Comparison of figures 3 and 5 shows that there was a significant difference between the east-west components of motion recorded in the basement and in the parking lot. Figures 4 and 6 , however, show that there was no significant difference between the north-south components of motion. To facilitate comparison, figures 7 and 8 show the zero-damped curves plotted on the same diagrams. It is seen that the east-west spectrum of the basement motion is approximately 40 per cent smaller 


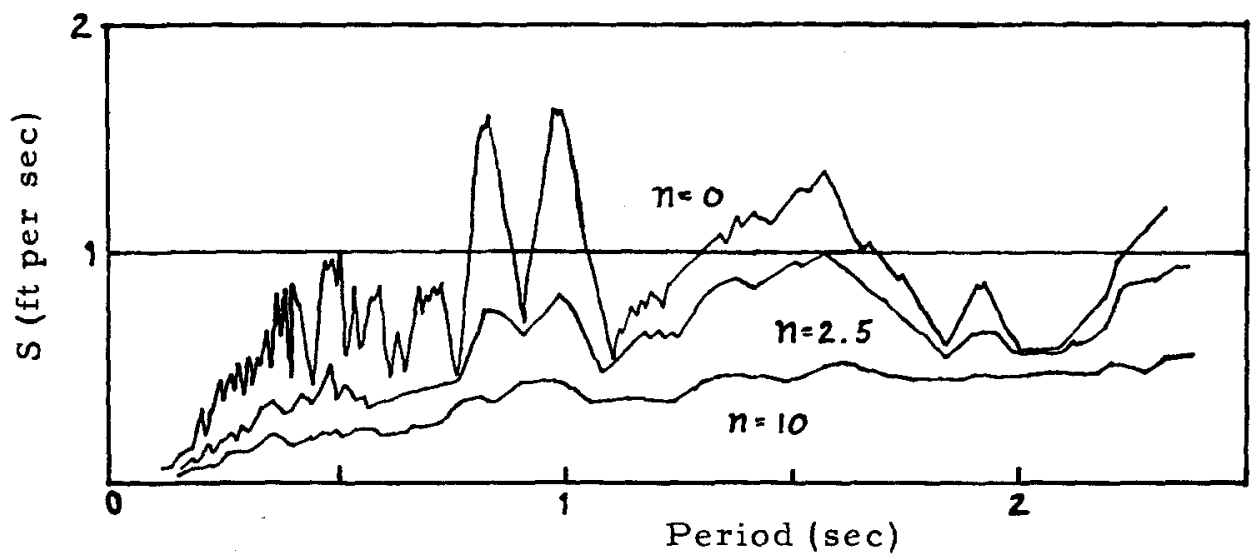

Fig. 5. Spectrum, Hollywood Storage parking lot; component E-W.

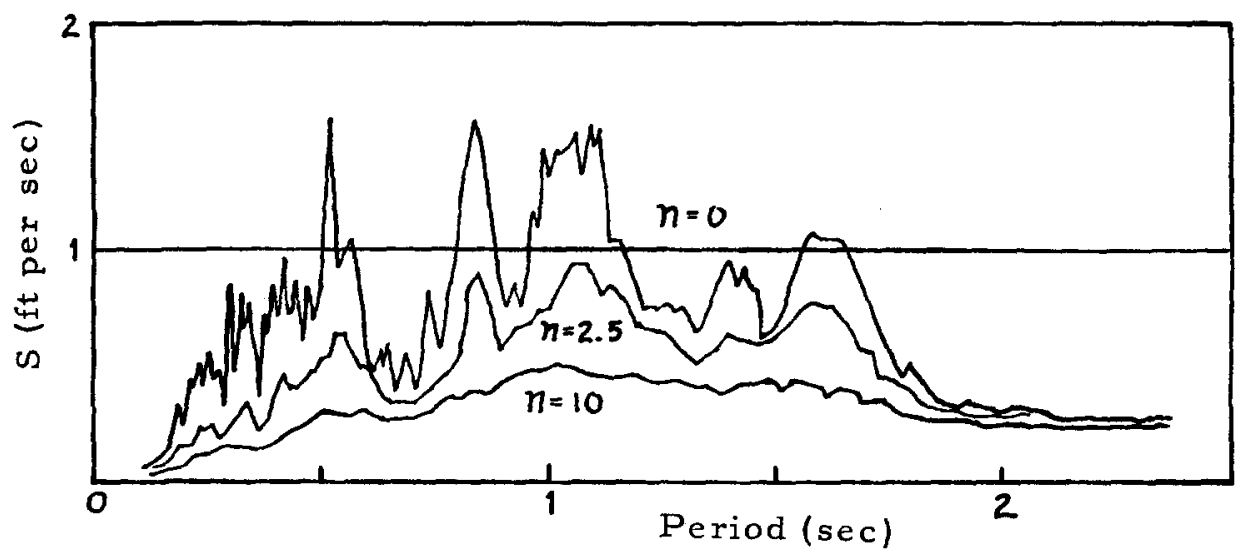

Fig. 6. Spectrum, Hollywood Storage parking lot; component N-S.

than the parking lot spectrum for periods less than 1 sec. For periods greater than 1 sec. the difference is less. Figure 8 shows that the spectra for north-south motion are essentially the same for basement and parking lot.

It is clear from the diagrams that the north-south component of motion was, for practical purposes, identical in the basement of the building and on the surface of the ground in the parking lot. There was, however, a measurable difference between the east-west components in the basement and in the parking lot. The fact that there was a difference in east-west components and not in north-south components can be attributed to the relative dimensions and stiffnesses in these directions. In the east-west direction the building was approximately four times as long and six times as stiff (as indicated by the periods) as in the north-south direction.

\section{EFFECT OF STIFFness}

The stiffer a building is, the more pronounced will be the horizontal coupling between building and ground. If the building were rigid (infinite stiffness), the entire 


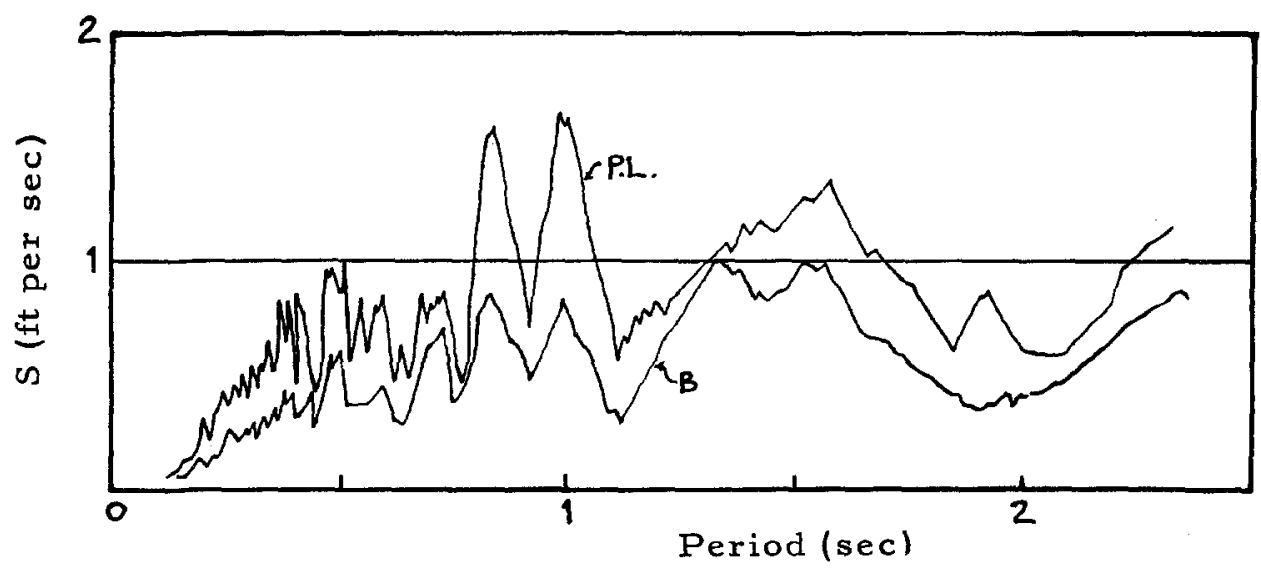

Fig. 7. Comparison, parking lot and basement; component E-W.

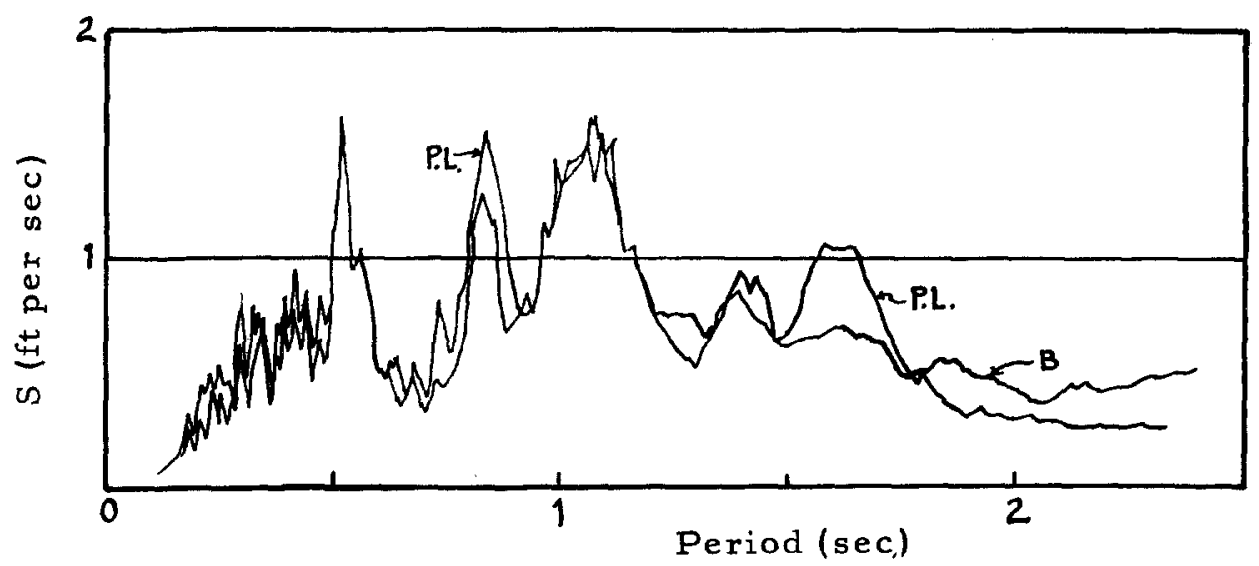

Fig. 8. Comparison, parking lot and basement; component N-S.

mass of the building would have to move if the base were moved. On the other hand, if the building were very flexible, the base could be moved back and forth without moving the center of mass of the building appreciably. During an earthquake there would be a large difference between the magnitude of force required to move the base of the rigid building and that required to move the base of the flexible building. Thus, if the soil surrounding the building were relatively soft, there would be larger deformations of the ground in the case of a rigid building than in the case of a flexible building.

Since the Hollywood Storage Company building is situated in rather soft alluvium, it would be reasonable to expect some difference in recorded motion between the stiff and the flexible directions, and it is likely that the differences observed for periods greater than 1 sec. can be attributed to this effect. However, the spectra curves show that the horizontal coupling between building and ground was not very large, for the following reason. If the horizontal coupling were strong, then the oscillation of the building in its fundamental mode would impart a periodic motion to 


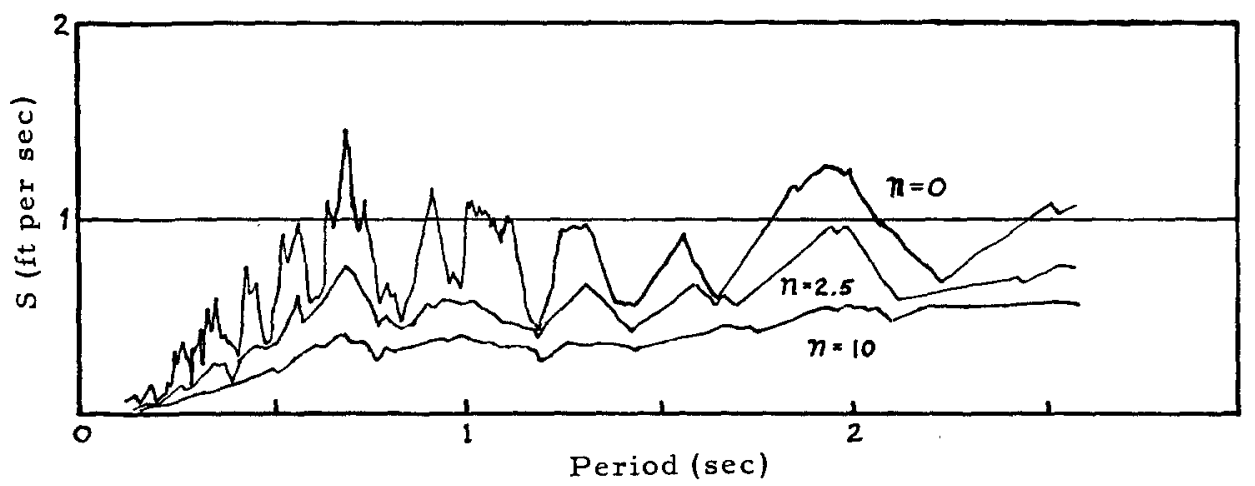

Fig. 9. Spectrum, Pasadena, component N-S.

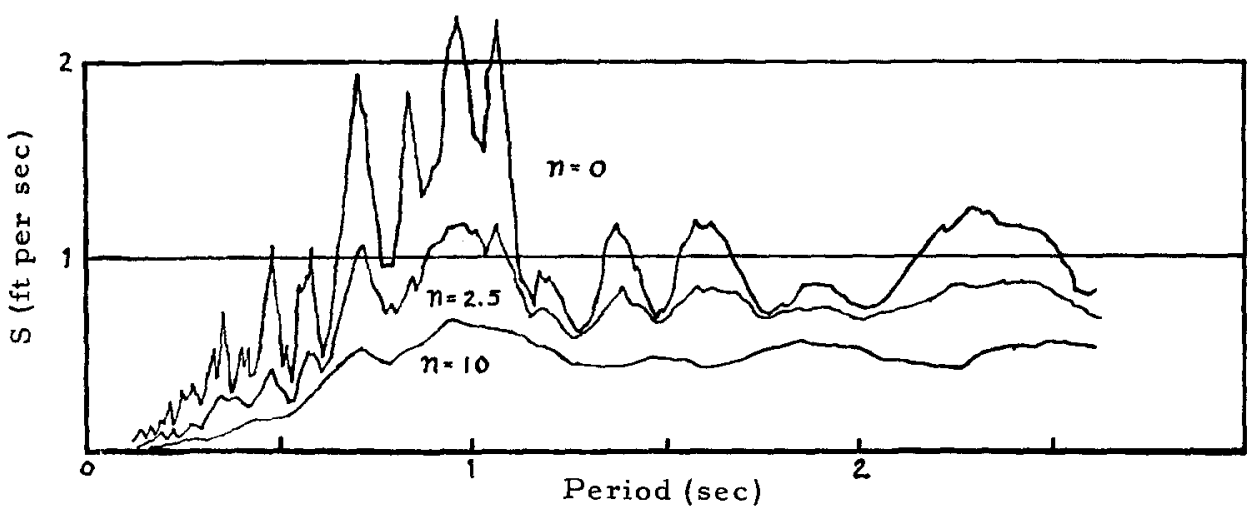

Fig. 10. Spectrum, Pasadena; component E-W.

the base and this would be recorded on the accelerogram. If this were the case, the spectrum curve for zero damping would have a peak at the fundamental period of vibration. In the case of the Hollywood Storage building this would mean a peak at 0.49 sec. period in the east-west spectrum and a peak at 1.2 sec. period in the north-south spectrum. Figure 7 shows that the east-west spectrum does not have a peak at 0.49 sec. and that the two large peaks that occur in the parking lot spectrum are greatly diminished in the basement spectrum. The north-south spectrum shows three large peaks, none of which occur at 1.2 sec. These three occur at $1.08,0.8$, and $0.5 \mathrm{sec}$. and the first two undoubtedly correspond to the two peaks in the east-west spectrum. The fact that these peaks are the fortuitous results of the random nature of the ground motion is illustrated by the peaks occurring in the Pasadena spectra shown in figures 9 and 10 . Since the Pasadena records were obtained in a low, stiff building, the fundamental periods would be well below any of the peaks on the spectra.

It can be concluded that in the case of the Hollywood Storage building the effect of horizontal ground coupling was not appreciable. It is thought that the difference in magnitude in figure 7 for periods greater than 1 sec. is indicative of the influence of the horizontal coupling. 


\section{Effect of Building Dimensions}

The fact that the east-west spectra (fig. 7) show an appreciable difference between parking lot and basement whereas the north-south spectra do not is attributed to the difference in building dimensions in these two directions. To see this, consider a displacement wave of 0.2 sec. period traveling through the ground with a velocity of 3,000 ft. per sec.; the half-wave length is then $300 \mathrm{ft}$. The $217 \mathrm{ft}$. length of the Hollywood Storage building is thus comparable to the half-wave length, and since the building is relatively inextensible it would have the effect of radically diminishing the amplitude of the wave. On the other hand, the $51 \mathrm{ft}$. width of the building is relatively small in comparison with the half-wave length and would not appreciably diminish the amplitude. Since the Hollywood Storage building is on soft alluvium having relatively low-wave velocities, it is reasonable that the $217 \mathrm{ft}$. length would tend to iron out the higher frequency components of the ground mo-
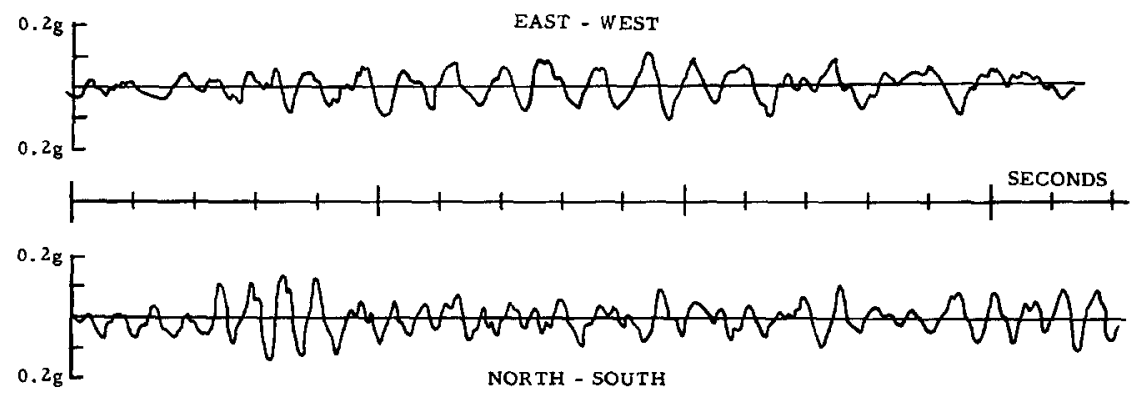

Fig. 11. Horizontal aceelerations, Hollywood Storage Building Penthouse, July 21, 1952.

tion. Such a diminution of high-frequency components is observable when the accelerations shown in figure 2 , parts $a$ and $b$, but is not so pronounced when parts $a$ and $b$ of figure 1 are compared.

\section{Conclusions}

On the basis of the seismograms of July 21, 1952, it is concluded that for the relatively large, heavy, and stiff Hollywood Storage building there was not a significant amount of ground coupling, and that in order for the ground coupling to be significant, in an engineering sense, the ground would have to be much softer than the socalled soft alluvium upon which the building rests. Buildings lighter and more flexible than the Hollywood Storage building would have even less ground coupling. If the Hollywood Storage building had been only one or two stories high, it would have undergone stresses approximately 40 per cent smaller in the $217 \mathrm{ft}$. direction than in the $51 \mathrm{ft}$. direction. It thus appears that on very soft ground a low, stiff building is benefited by having large dimensions so long as the foundation structure is sufficiently strong.

\section{ACKNowleDgMents}

The accelerograms used in this study were obtained from the Seismological Field Survey of the U. S. Coast and Geodetic Survey.

Division of Engineering,

Califormia Institute of Technology, Pasadena, Calif. 